\title{
Removal of Pollutants in Soak Water Resulting from Parboiling of Paddy
}

\section{H.W.G.I. Karunaratne and M.Y. Gunasekera}

Abstract: Rice is the staple diet in Sri Lanka where parboiled rice is becoming fast popular. The parboiling process involves three main steps namely soaking, steaming and drying which improves various characteristics of rice. A significant amount of water is consumed in soaking operation. The wastewater generated from this operation is mostly discharged to inland water bodies and surface lands. The continuous discharge of this effluent is of environmental concern.

Lab scale experiments were carried out to investigate the effectiveness of different wastewater treatment methods for removal of pollutants in soak water resulting from hot soaking of red rice variety named LD 356. Biological treatment methods such as aerobic, anaerobic and physical treatment methods such as coagulation and adsorption were investigated. Removal of pollutants by aquatic plants and biological treatment using various microbial sources such as cow dung, rice straw, pond water and paddy field soil were also investigated. Results show that microbial sources from pond water and paddy field soil were able to reduce COD in soak water by $96 \%$ and $94 \%$ respectively at $\mathrm{pH} 8$ under aerobic and dark conditions. In seven days, $62 \%$ and $65 \% \mathrm{COD}$ removal were observed by water hyacinth and salvinia respectively. Combined treatment of anaerobic digestion and coagulation was able to remove $94 \%$ COD while the combination of anaerobic digestion and adsorption removed $95 \%$ COD

Keywords: wastewater, paddy parboiling, pollutant removal, hot soaking

\section{Introduction}

Paddy parboiling is a method practiced widely in Sri Lanka today to improve milling quality and other characteristics of rice. It involves soaking of paddy, steaming, drying and milling. Depending on the parboiling method used, paddy is soaked for different periods of time under different conditions. The characteristics of wastewater produced from this process vary depending on the soaking method used [1].

Rice Processing Research and Development Centre (RPRDC) of Sri Lanka has developed different rice processing methods for paddy parboiling. The soaking operation in parboiling process could be done in two different ways. They are cold soaking method and hot soaking method. In hot soaking method hot water at $700^{\circ} \mathrm{C}$ is added to paddy placed in cement tanks and soaked for 10 hours. If the temperature is kept at $70^{\circ} \mathrm{C}$, soaking should be done for only about 2-4 hours [2]. In cold soaking method soaking should be done for 3-4 days. The water in the soaking container should be changed every 12 hours [2]. But practically it is observed that mill owners do not follow these steps strictly. They change soak water every day instead of every 12 hours. The fresh paddy is soaked for a longer time period and the paddy somewhat old is soaked within a shorter time period. The quality of the parboiled rice will depend on the soaking time. If the soaking time is not sufficient breakage of grains during milling is high. General characteristics of parboil wastewater especially values for Chemical Oxygen Demand (COD) and Biological Oxygen Demand (BOD) reported in literature [1] are significantly higher than the discharge standards applicable in Sri Lanka. In most rice mills, effluent is discharged into inland surfaces or surrounding water bodies without any treatment. The effluents discharged from rice mills do not contain toxic compounds [1], but the continuous discharge in to the environment can cause adverse effects. The stagnant water emits off odours due to fermentative changes. These off odours are carried away by wind. The growth of natural flora can also get affected by this effluent. Since

Ms.H.W.G.I. Karunaratne, B.Sc. Eng. (Ions) (Moratuza), Research Student, Chemical \& Process Engineering Department, University of Moratuma, Sri Lanka

Eng. Dr.(Ms) M.Y. Gunasekera B.Sc. Eng. (Hons) (Moratuza), M.Eng. (Moratuwa), PhD (UK), AMIE(Sri Lanka)Senior Lecturer, Chemical \& Process Engineering Departnent, University of Moratuva, Sri Lanka 
parboil wastewater is rich in nutrients it encourages the growth of algae. This growth could lead to eutrophication in tanks resulting in low dissolved oxygen content and hence the reduction in water quality. Aquatic life is affected by water quality and deficit of dissolved oxygen (DO). Due to the colour and turbidity of wastewater, low penetration of sunlight into waterways affects the photosynthesis process. Therefore it is necessary to investigate pollutant removal methods for this effluent.

\section{Literature Review}

\subsection{Characteristics of parboiled paddy wastewater}

Biochemical characteristics and microbial population in soak water effluents from various parboiling methods practiced today are available in literature [1]. These literature reveals that the biochemical characteristics of the parboiled wastewater such as reducing sugars, total sugars, amino nitrogen, total phenols, organic carbon, biochemical oxygen demand, chemical oxygen demand vary depending on the parboiling method used. According to studies done by Ramalinlgam and Raj [1], five different parboiling methods are described mainly practiced in India namely household method, cold soaking method, double steaming method, hot soaking method and pressure parboiling method. The duration and temperature of the paddy soaking operation allow different levels of carbohydrate losses to the wastewater and this can be seen in compositional variations of the effluent [3]. The microbial population observed in soak water is a mixed microflora, comprising different groups of organisms [1].

\subsection{Pollutant removal in wastewater from soaking operation}

Research done by Queiroz et al. [4], to evaluate the kinetics of removal of nitrogen and organic matter from parboiled paddy effluent by using cyanobacteria has shown that maximum efficiency for the removal of organic matter expressed as chemical oxygen demand (COD) and total nitrogen (N-TKN) occurred after 15 hours of cultivation of the cyanobacteria in wastewater. The COD and N-TKN removal efficiencies were $83.44 \%$ and $72.74 \%$ respectively. Environment and Management
Lanka (Private) Limited in association with the Department of Chemical Engineering of the University of Moratuwa has developed a treatment method for effluent resulting from cold soaking of paddy for a white rice variety [2]. Their results have shown that the Oxidation Ditch method is very efficient and involves a low cost in treating this effluent.

\section{Methodology}

Removal of pollutants from paddy soak wastewater by different methods was investigated for hot soaking of a red rice variety. An amount of 1.3 litres of hot water at $70^{\circ} \mathrm{C}$ was added to $1 \mathrm{~kg}$ of raw paddy and soaked at $70^{\circ} \mathrm{C}$ for 3 hours. Then soak water was drained and collected. The wastewater collected from this paddy soaking operation is referred to as 'soak water' in this study. The pollutant removal study was done using this wastewater. The methods used are aerobic treatment with aeration, anaerobic treatment, coagulation, adsorption and aquatic plants based treatment.

\subsection{Aerobic Treatment}

In this study the wastewater was inoculated with some bacterial source which is believed to contain cyanobacteria. Pond water, fish tank water, paddy field soil and rice straw are some of the sources containing cyanobacteria [5], [6]. Therefore, the pollutant removal using above sources were analysed.

Using pond water as the microbial source, pollutant removal was studied under different conditions. Experimental studies done by Queiroz et al. [4] in removal of nitrogen and organic matter from parboiled rice effluent by cyanobacteria have used conditions such as temperature at $30^{\circ} \mathrm{C}, \mathrm{pH} 8$, in the absence of light under constant aeration permitting saturation with oxygen [4]. In this work also similar experimental conditions were adopted. A pond water volume of $2 \mathrm{ml}$ was added to 300 $\mathrm{ml}$ of soak water samples and tests were carried out under following four conditions.

> Sample was aerated by bubbling under normal day light conditions. The $\mathrm{pH}$ was maintained at its natural wastewater $\mathrm{pH}$ value which was 6.5 .

> Sample was aerated by bubbling in a dark environment (absence of light). 
The $\mathrm{pH}$ was maintained at its natural wastewater $\mathrm{pH}$ value which was 6.5 .

> Sample $\mathrm{pH}$ was adjusted to 8 and aerated by bubbling under normal day light conditions.

$>$ Sample $\mathrm{pH}$ was adjusted to 8 and aerated by bubbling in a dark environment.

A soak water sample without inoculating with an external microbial source was also aerated by bubbling at $\mathrm{pH} 8$ in the dark environment condition.

The COD removal in all above samples was measured. The value of COD was determined according to Standard Methods for the Examination of Water and Wastewater using the closed reflux, titrimetric method [7].

Paddy field soil and fish tank water were also used as microbial sources to study the removal of pollutants in paddy soak wastewater. Paddy field soil was dissolved in water and kept for 4 hours. A volume of $5 \mathrm{ml}$ from the supernatant was taken and added to $300 \mathrm{ml}$ of soak wastewater. The $\mathrm{pH}$ of this sample was adjusted to 8 and aerated by bubbling air in the absence of light. Variation of COD in this sample with time was measured. Above experiment was carried out for other source of microorganism that is fish tank water by adding $5 \mathrm{ml}$ into soak wastewater samples.

\subsection{Anaerobic Treatment}

Lab scale batch type anaerobic tests were carried out to find the anaerobic digestibility of paddy soak wastewater. Anaerobic tests were done for two soak water samples. In one sample, cow dung was added as microbial source. In the other sample only micro organisms present in the wastewater was used.

Cow dung weight of $5 \mathrm{~g}$ was dissolved in $20 \mathrm{ml}$ paddy soaked water and kept for 24 hours in a closed container. A bottle was filled with wastewater up to $80 \%$ of its volume and $10 \mathrm{ml}$ from supernatant of cow dung dissolved soak water was added. A syringe was connected as shown in figure 1 to take liquid samples for the analysis. One end of a $U$ tube filled with Sodium chloride and Citric acid solution was connected to gas out flow line of the anaerobic digester which is marked as 08 in figure 1.The bottle connected with the $U$ tube and syringe was then sealed.

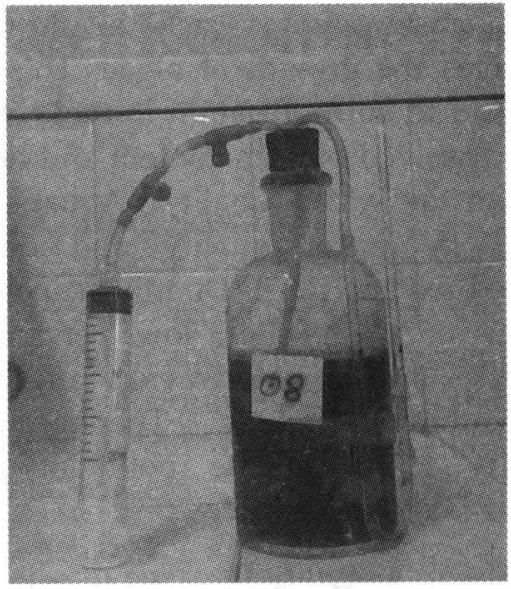

Figure 1: Lab scale anaerobic digester

The same test was carried out for another sample, without adding cow dung dissolved solution. The COD removal of the wastewater in the digester was measured up to 49 days.

\subsection{Coagulation}

Effect of coagulant dosage and $\mathrm{pH}$ on removal of COD and turbidity were investigated using the jar tester. Aluminium Sulphate was used as the coagulant. The turbidity of the soak water was measured by absorptometric method using DR/890 colorimeter. The value of COD was analysed using the closed reflux, titrimetric method [7].

\subsubsection{Effect of coagulant dosage}

Solutions with different concentrations of Aluminium Sulphate were prepared. The $\mathrm{pH}$ value of soak water was 6.5 . While mixing the wastewater samples of $450 \mathrm{ml}$ volume each at $100 \mathrm{rpm}$ in the jar tester, different dosages of coagulant (Aluminium Sulphate) were added. Mixing at $100 \mathrm{rpm}$ was continued for 1 minute. Then, the suspensions were mixed at $35 \mathrm{rpm}$ for 20 minutes [8]. Stirring was stopped and the samples were allowed for settling of flocs. Turbidity and COD of the settled water were measured by taking samples from the supernatant from just below the surface of water in the beakers.

\subsubsection{Effect of $\mathrm{pH}$}

The $\mathrm{pH}$ of paddy soaked water samples were adjusted to different values by adding Sodium Hydroxide and Hydrochloric acid. While mixing the soak water samples of $450 \mathrm{ml}$ volume each at $100 \mathrm{rpm}$, coagulant was added. Optimum dosage of coagulant was determined 
from the previous test described in section 3.3.1, and that dosage was used in this test. After adding the coagulant, the test was continued as in the previous test described in 3.3.1.

\subsection{Adsorption}

Adsorption of pollutants in soak water by Granular Activated Carbon (GAC) was determined for both modes of operation, batch adsorption and continuous fixed bed adsorption.

\subsubsection{Batch Adsorption}

Batch experiments were carried out to test the effects of adsorbent dosage, particle size and $\mathrm{pH}$ on adsorption. Variation of COD with one above parameter was determined while keeping other parameters constant. GAC added wastewater samples of $200 \mathrm{ml}$ each were kept mixing on the orbital shaker at $200 \mathrm{rpm}$ for all these batch adsorption experiments. The effect of adsorbent dosage was investigated by adding different dosages of adsorbent varying from $1 \mathrm{~g}$ to $4 \mathrm{~g}$ into these $200 \mathrm{ml}$ soak water samples. The effect of particle size on COD removal was observed by adding a same weight of GAC in different particle size ranges varying from $250-500 \mu \mathrm{m}$ to $1000-1400 \mu \mathrm{m}$ into soak water samples. For the investigation of COD reduction at different $\mathrm{pH}$ values, sample $\mathrm{pH}$ was adjusted to $4,6,8$ and 10 by adding $\mathrm{HCl}$ and $\mathrm{NaOH}$.

\subsubsection{Fixed bed Adsorption}

The effects of bed depth and effluent flow rate through the packed bed on adsorption were investigated. A glass column with internal diameter of $3 \mathrm{~cm}$ was packed with GAC of 500$1000 \mu \mathrm{m}$ particle size. Soak water was sent downward through the packed bed with the aid of a pump. The COD in the outlet stream at different times were measured. Effect of bed depth was determined by changing the packing height at same flow rate. To determine the effect of flow rate, soak water was sent at different flow rates at same packing height.

\subsection{Treatment using aquatic plants}

Pollutant removal from wastewater by aquatic plants, water hyacinth and salvinia were observed. Water hyacinth plants of approximately the same size in appearance were kept in basins filled with soak water and tap water as shown in figure 2. Each basin was filled up to the same level. Growth of the plants in both samples was compared for 10 days. Further the variation of COD in soak wastewater with time was also determined.

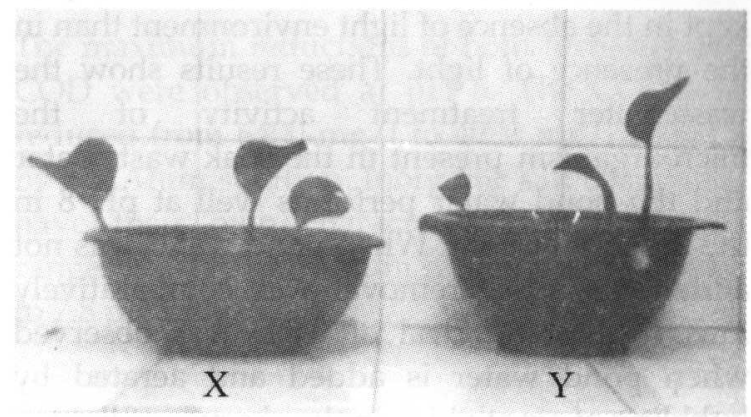

Figure 2: Water hyacinth plants kept in soak water (x) and tap water (y)

\subsection{Combined Treatment}

\subsubsection{Anaerobic Digestion and Coagulation}

Anaerobic digested soak water samples using cow dung as the microbial source was coagulated with $5 \%$ alum.

\subsubsection{Anaerobic Digestion and Batch Adsorption}

Batch adsorption test was carried out using $4 \mathrm{~g}$ of 500-710 $\mu \mathrm{m}$ particle size GAC in $200 \mathrm{ml}$ of anaerobically treated soak wastewater sample.

\section{Results and Discussion}

\subsection{Aerobic treatment}

Figure 3 shows the COD removal using $2 \mathrm{ml}$ pond water as the microbial source in the presence of light and in the absence of light at $\mathrm{pH}$ values 6.5 and 8 under aeration by bubbling of air. The results of a sample without adding pond water are also shown in figure 3 . This sample was kept in a dark environment and at $\mathrm{pH} 8$.

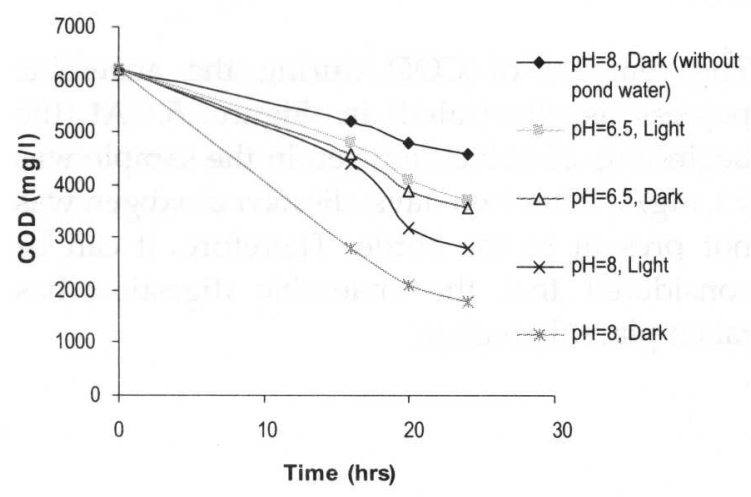

Figure 3: Variation of COD with time in different $\mathrm{pH}$ values in the presence of light and absence of light 
The removal of COD was higher at $\mathrm{pH} 8$ in both samples kept in the presence of light and in the absence of light compared with samples at $\mathrm{pH}$ 6.5. At both $\mathrm{pH}$ values, higher percentage removal of COD was observed in the samples kept in the absence of light environment than in the presence of light. These results show the wastewater treatment activity of the microorganism present in the soak wastewater and the pond water performs well at $\mathrm{pH} 8$ in the absence of light. When pond water was not added, the COD removal was comparatively low. Highest removal of COD was observed when pond water is added and aerated by bubbling of air at $\mathrm{pH} 8$, in the absence of light.

The COD removal in soak wastewater, when 5 $\mathrm{ml}$ of paddy soil dissolved water, pond water and fish tank water were used as the microbial source separately are shown in Figure 4.

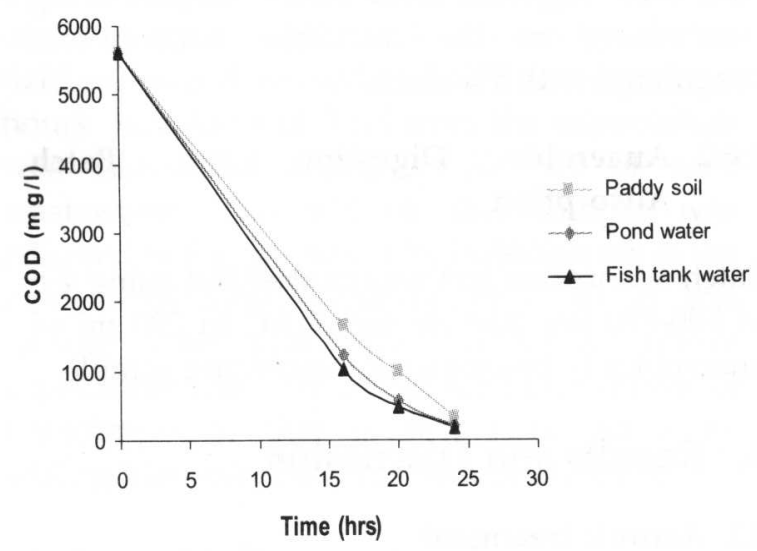

Figure 4: Variation of COD with time at $\mathrm{pH} 8$ with aeration.

All three sources of microorganism showed similar curves and approximately the same fate of COD removal after 24 hours. .

\subsection{Anaerobic Treatment}

The removal of COD during the anaerobic process is illustrated in Figure 5. At the beginning, dissolved oxygen in the sample was $4.1 \mathrm{mg} / \mathrm{l}$. After two days, dissolved oxygen was not present in the bottle. Therefore, it can be considered that the anaerobic digestion has taken place thereafter.

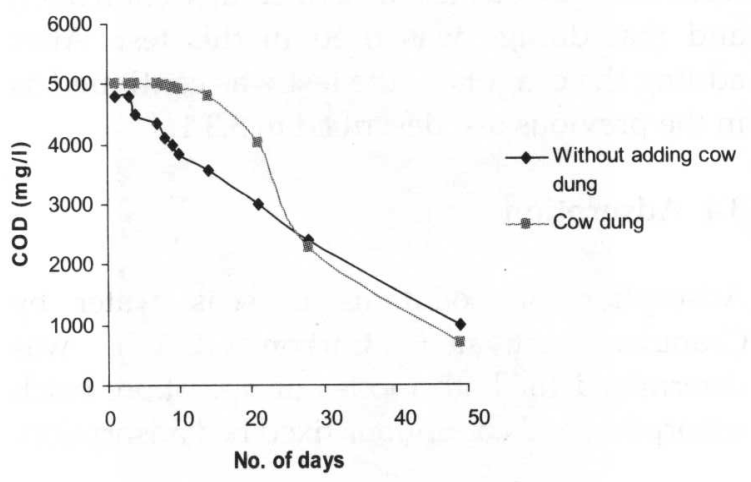

Figure 5: Variation of COD with time in the absence of air

Initially the COD was higher in cow dung added sample. It may be due to organic matter in cow dung. But after around 28 days, COD in the cow dung added sample was lower than the other sample.

\subsection{Coagulation}

\subsubsection{Effect of Coagulant dosage}

Figure 6 shows the variation of turbidity and COD in soak water with different dosages of alum. The $\mathrm{pH}$ of the paddy soaked water was 6.5 and the experiments were carried out at room temperature that is $30^{\circ} \mathrm{C}$. After mixing at $35 \mathrm{rpm}$ for 20 minutes, samples were kept for 2 hours to settle the flocculants formed. Then the samples were taken using a pipette for testing.

\subsubsection{Variation of turbidity with coagulant dosage}

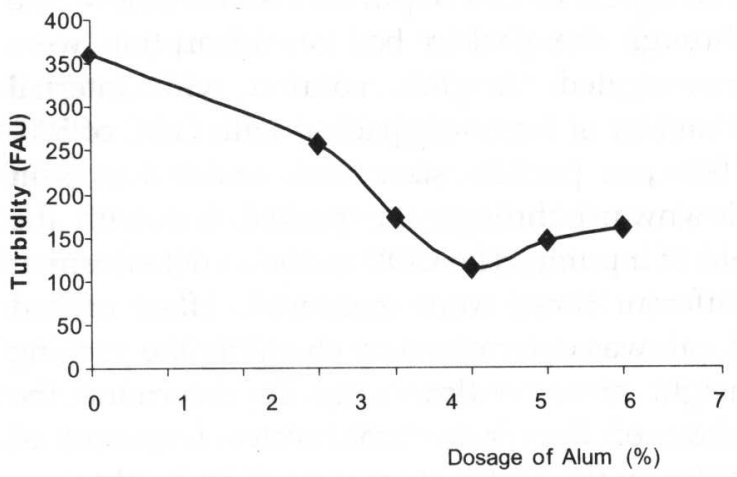

Figure 6: Effect of coagulant dosage on turbidity

Turbidity has decreased with increase in alum dosage up to $5 \%$ alum and increased thereafter as shown in Figure 6. 


\subsubsection{Variation of COD with coagulant dosage}

In the samples, without adding coagulant and adding 3\% coagulant solution the COD was not reduced (Figure 7 ).

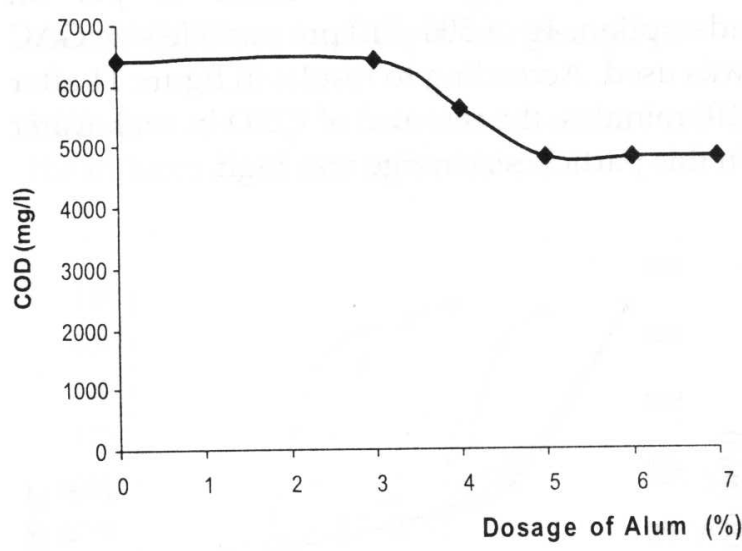

Figure 7: Effect of coagulant dosage on COD

The COD of samples were reduced to 4800 $\mathrm{mg} / 1$ at coagulant dosages of $5 \%, 6 \%$ and $7 \%$. Above results of both turbidity and COD tests, show that $10 \mathrm{ml}$ of $5 \%$ alum in $450 \mathrm{ml}$ of soak water is sufficient to reduce COD in wastewater to $4800 \mathrm{mg} / \mathrm{l}$ under above test conditions.

\subsubsection{Effect of $\mathrm{pH}$}

The $\mathrm{pH}$ range in which a coagulation process occurs is very important. In some $\mathrm{pH}$ ranges alum may become soluble in water. Effect of $\mathrm{pH}$ on turbidity and COD removal were investigated using $5 \%$ Alum dosage which showed the minimum turbidity and maximum COD removal.

\subsubsection{Variation of turbidity with $\mathrm{pH}$}

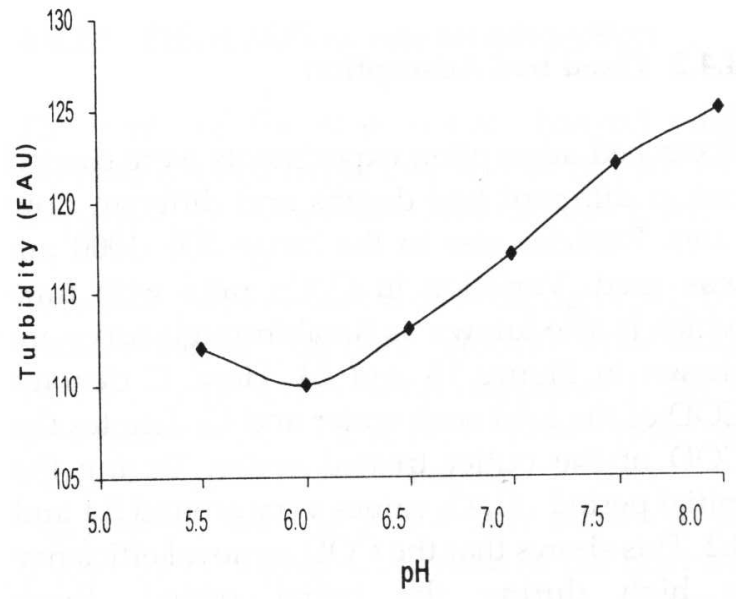

Figure 8: Effect of $\mathrm{pH}$ on turbidity
The minimum turbidity after coagulation was observed at $\mathrm{pH} 6$.

\subsubsection{Variation of COD with $\mathrm{pH}$}

The maximum reductions of both turbidity and COD were observed at $\mathrm{pH}$ 6. The COD was reduced from $6400 \mathrm{mg} / 1$ to $4000 \mathrm{mg} / 1$ at $\mathrm{pH} 6$ by $5 \%$ Alum solution. Inorganic salt coagulants have their own characteristic optimum $\mathrm{pH}$ ranges [9]. Typically alum can be effective in 5.5 to $7.8 \mathrm{pH}$ range.

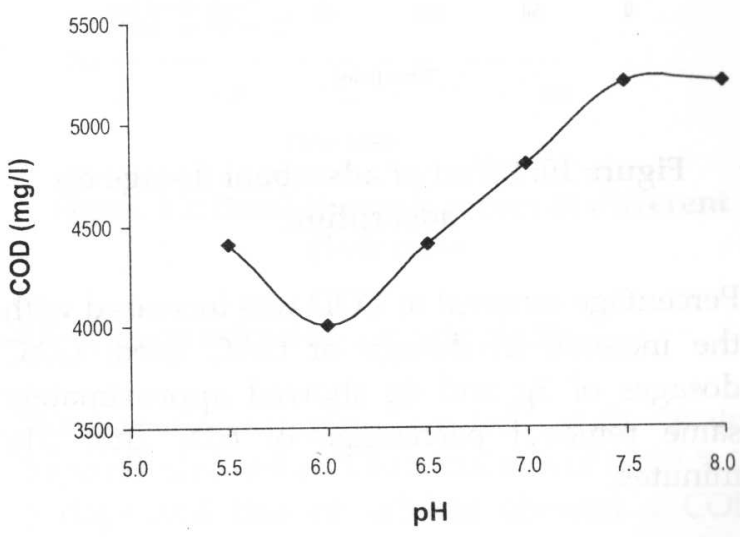

Figure 9: Effect of $\mathrm{pH}$ on COD

Results show that for this soak water at $30^{\circ} \mathrm{C}$ alum was most effective at $\mathrm{pH} 6$.

\subsection{Adsorption}

\subsubsection{Batch Adsorption}

Figures 10, 11 and 12 illustrate the effect of adsorbent dosage, particle size and wastewater $\mathrm{pH}$ on commercial GAC adsorption in paddy soak wastewater. Effects of adsorbent dosage and particle size were investigated at $\mathrm{pH} 6.4$, which was the $\mathrm{pH}$ value of this soak water.

\subsubsection{Effect of adsorbent dosage on adsorption}

Different dosages of GAC particle size range $710-1000 \mu \mathrm{m}$ were used for treating $200 \mathrm{ml}$ of soak water samples. All samples have shown a COD reduction with time. 


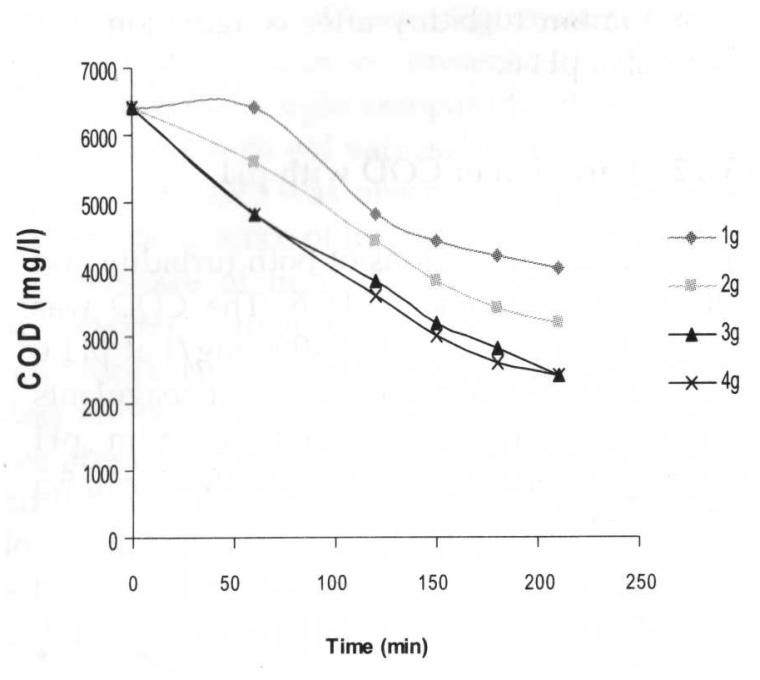

Figure 10: Effect of adsorbent dosage on adsorption

Percentage removal of COD was increased with the increase in dosage of GAC used. GAC dosages of $3 \mathrm{~g}$ and $4 \mathrm{~g}$ showed approximately same removal percentage of $62 \%$ after 210 minutes.

\subsubsection{Effect of particle size of GAC on adsorption}

Adsorbent dosage of $4 \mathrm{~g}$ was selected for this experiment because it showed the maximum COD removal in the above experiment. Particle size was measured in $\mu \mathrm{m}$.

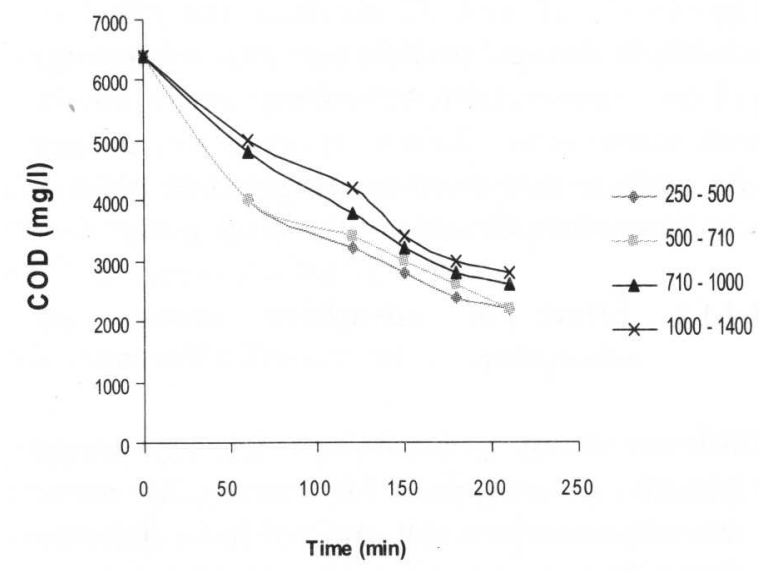

Figure 11: Effect of particle size on adsorption

Highest COD removal was observed in the samples, with 250-500 $\mu \mathrm{m}$ and 500-710 $\mu \mathrm{m}$ particle size ranges of activated carbon, adsorbed after 210 minutes. When the particle size of activated carbon increased, the COD removal has shown a decrease. The finer the particles size of the activated carben, the better the adsorption of pollutants.

\subsubsection{Effect of $\mathrm{pH}$ on adsorption}

For the investigation of effect of $\mathrm{pH}$ on adsorption, $4 \mathrm{~g}$ of $500-710 \mu \mathrm{m}$ particle size GAC was used. According to results in figure 11 after 210 minutes, the removal of COD in soak water in this particle size range was high.

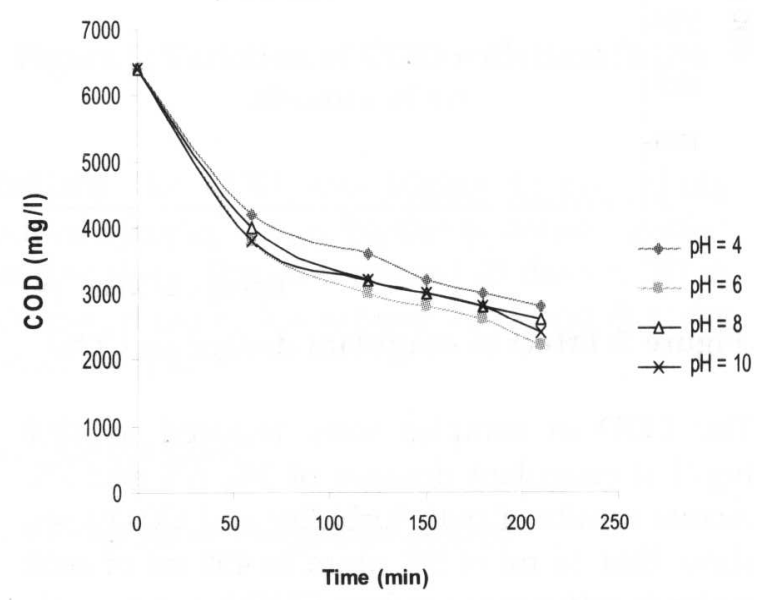

Figure 12: Effect of $\mathrm{pH}$ on adsorption

Though between 60 minutes and 210 minutes, 250-500 $\mu \mathrm{m}$ particle size showed a higher removal percentage than $500-710 \mu \mathrm{m}$ particle size, the 250-500 $\mu \mathrm{m}$ particles used sample liquid showed a slight black colour. However the treated soak water was clear when 500-710 $\mu \mathrm{m}$ particle size range adsorbent was used. At all $\mathrm{pH}$ values investigated here, COD has decreased with time. COD reduction was low at $\mathrm{pH} 4$, being $53 \%$. At $\mathrm{pH} 8$ and 10 , the difference in COD removal was not significant. The sample having a $\mathrm{pH} 6$, showed the maximum COD removal of $66 \%$.

\subsubsection{Fixed bed Adsorption}

Fixed bed adsorption experiments were carried out at different bed depths and different flow rates. Particles size in the range $500-1000 \mu \mathrm{m}$ was used. Variation in $\mathrm{C} / \mathrm{Co}$ ratio with time which is also known as Breakthrough curve are shown in Figure 13 and 14. Here, $\mathrm{C}$ denotes COD of the inlet soak water and $\mathrm{C}_{0}$ denotes the COD of the outlet treated water. During the initial period $C / C_{0}$ values vary around 0.1 and 0.2. This shows that the COD removal efficiency is high during the initial period. Fresh adsorbent can adsorb a higher amount of pollutants. With the time COD of the outlet stream increases, so that the $\mathrm{C} / \mathrm{Co}$ ratio also 
increases. After the adsorbent bed is saturated with adsorbate, $\mathrm{C} / \mathrm{C}_{0}$ reaches to 1 . At this point both influent and effluent COD of the fixed bed are same. Afterwards wastewater is not treated by the adsorbent.

\subsubsection{Effect of bed depth on adsorption}

Different bed depths were used while keeping the influent flow rate at $7 \mathrm{ml} / \mathrm{min}$.

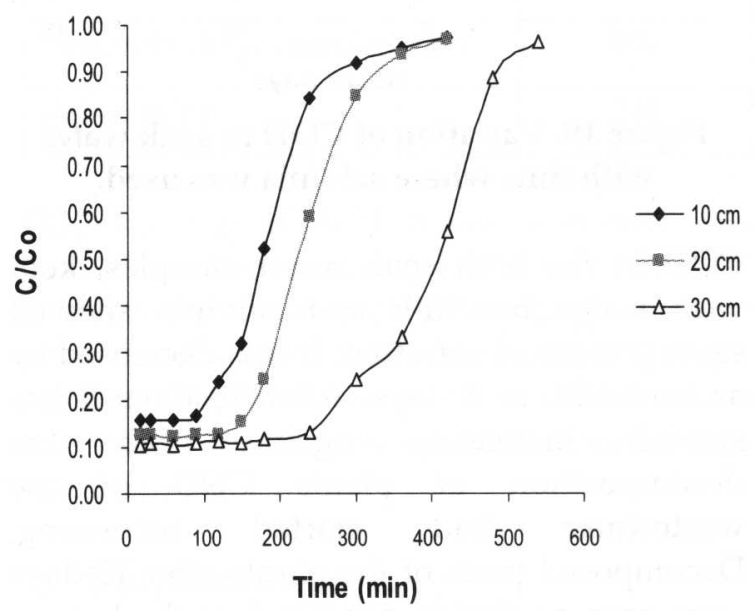

Figure 13: Breakthrough curves at different bed depths

Experiment results follow the characteristic ' $\mathrm{S}$ ' shape curve for fixed bed adsorption. Increasing the bed depth increases the time taken for bed saturation and thereby the volume that could be treated before bed saturation. A given mass of adsorbent can only adsorb a fixed amount of adsorbate. Lower the bed depths, higher the slope in the breakthrough curve and lesser the time taken to saturate the bed.

\subsubsection{Effect of flow rate on adsorption}

Flow rate of the soak water changed while keeping the bed depth constant at $20 \mathrm{~cm}$. GAC of particle size range $500-1000 \mu \mathrm{m}$ was used.

Low flow rates of soak water through GAC bed showed higher pollutant removal. This shows that the contact time is an important factor in adsorption. At $15 \mathrm{ml} / \mathrm{min}$ flow rate the adsorbent-adsorbate contact time is significantly less. So it is clearly shown in the Figure 14 by higher COD ratio of the inlet and outlet samples. Initial COD removal percentages were $90 \%, 87 \%$ and $76 \%$ at the flow rates of $3 \mathrm{ml} / \mathrm{min}, 7 \mathrm{ml} / \mathrm{min}$, and $15 \mathrm{ml} / \mathrm{min}$ respectively.

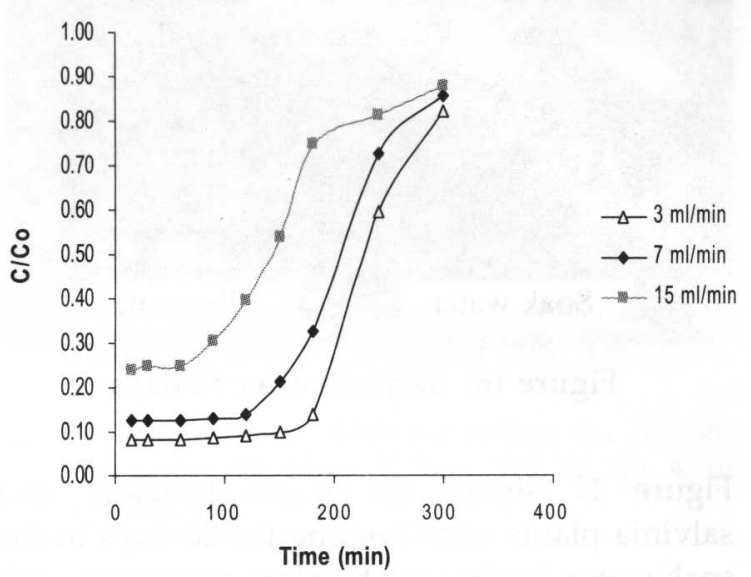

Figure 14: Breakthrough curves at different flow rates

\subsection{Treatment using aquatic plants}

Wastewater samples treated with water hyacinth showed a COD reduction of $62.50 \%$ in 5 days and that of salvinia showed a COD reduction of $65.62 \%$ in 7 days. After 10 days both plants kept in soak waters, started decaying and COD in the wastewater started increasing, while the plants kept in tap water remained, as they were when the experiment started.

Figure 15 and Figure 16 show the water hyacinth and salvinia plants respectively in the soak water and tap water after 10 days.

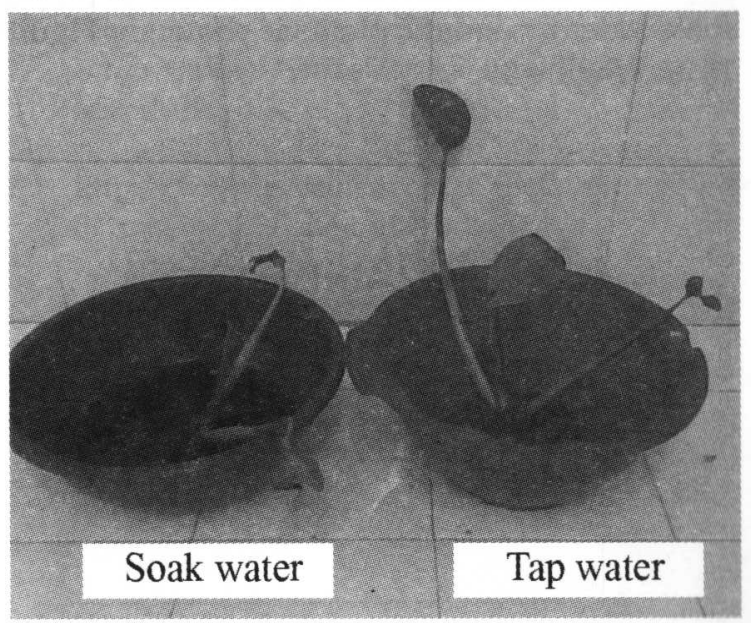

Figure 15: Water hyacinth after 10 days 


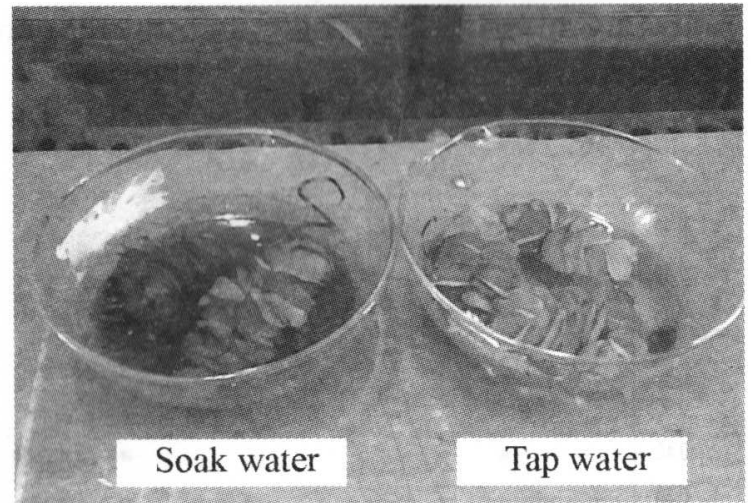

Figure 16: Salvinia after 10 days

Figure 17 shows the water hyacinth and salvinia plants after keeping for 20 days in the soak water. In the aquatic plant containers with tap water a significant change in water volume was not observed, while in containers with soak water the water volume has completely disappeared.

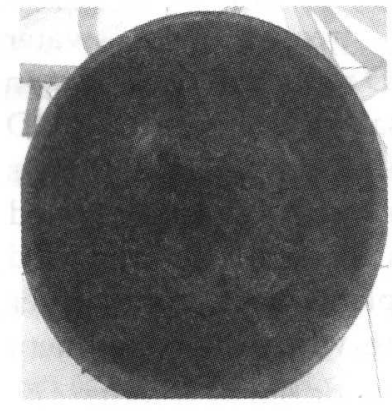

Water hyacinth

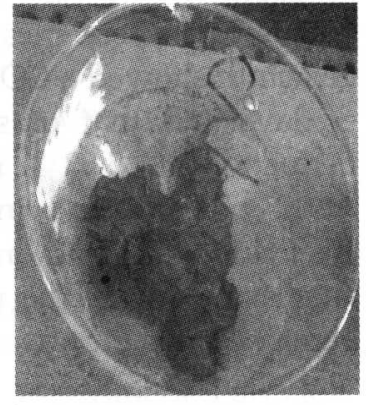

Salvinia
Figure 17: water hyacinth and salvinia plants after keeping 20 days in the soak water.

Plants kept in soak water were dead after 12 days. The COD removal of pollutants in paddy soak water by aquatic plants is shown in Figure 18 and Figure 19.

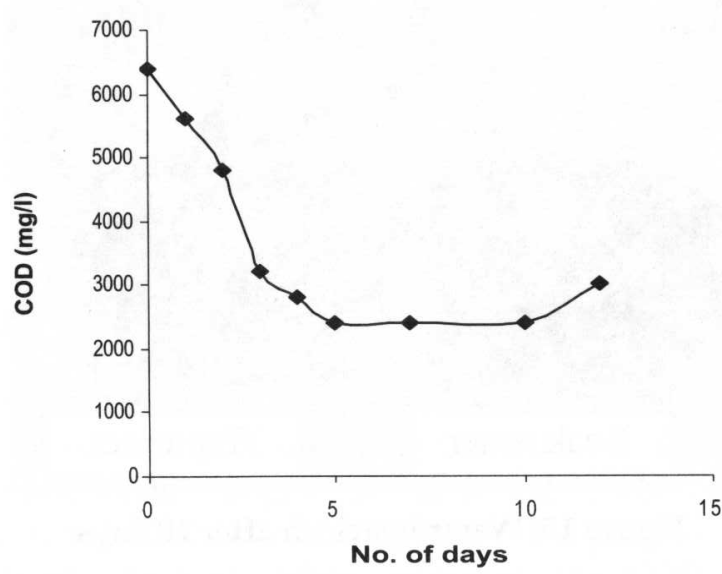

Figure 18: Variation of COD in soak water with time where water hyacinth was used.

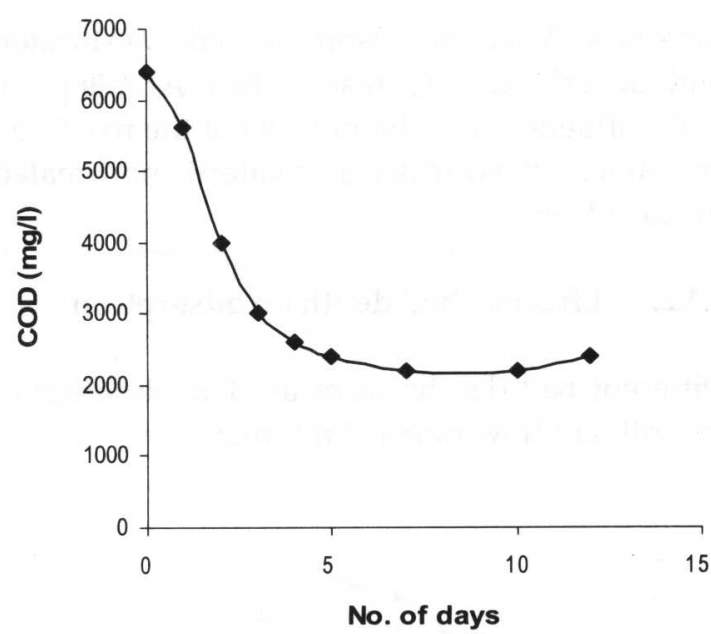

Figure 19: Variation of COD in soak water with time where salvinia was used.

COD in the both soak water samples, kept with water hyacinth and salvinia showed same pattern of variation. It was decreased by around $62 \%$ in 5 days. After 10 days it has started increasing again. With the decomposition of plants COD of the wastewater had started increasing. Decomposed parts of the plants after 15 days were seen as sludge deposited at the bottom of the container. In 20 days watery appearance disappeared and a dried solid was observed.

\subsection{Combined treatment}

\subsubsection{Anaerobic Digestion and Coagulation}

Table 1 shows the results of treating paddy soak wastewater in an anaerobic digester followed by coagulation.

Table 1: COD removal by combined treatment of anaerobic digestion and coagulation

\begin{tabular}{|l|c|}
\hline \multicolumn{1}{|c|}{ Treatment Method } & COD (mg/l) \\
\hline Initial & 5020 \\
\hline Anaerobic Digestion (after 49 days) & 720 \\
\hline Coagulation & 270 \\
\hline
\end{tabular}

The COD value was reduced by $94.62 \%$. The final COD was below the standards for discharging the wastewater into irrigation lands which is $400 \mathrm{mg} / 1$. 


\subsubsection{Anaerobic Digestion and Batch Adsorption}

The sample subjected to batch adsorption after anaerobic digestion showed the results in table 2.

Table 2: COD removal by combined treatment of anaerobic digestion and batch adsorption

\begin{tabular}{|l|c|}
\hline \multicolumn{1}{|c|}{ Treatment Method } & COD (mg/l) \\
\hline Initial & 5020 \\
\hline Anaerobic Digestion (49 days) & 690 \\
\hline Adsorption & 240 \\
\hline
\end{tabular}

COD removal of $95.21 \%$ was observed after both above treatment steps. The value of COD is below the wastewater discharging standards into inland surface waters which is $250 \mathrm{mg} / 1$. However the characteristic brown colour of red rice soaked water persisted in the treated soak water sample.

\section{Conclusions}

Highest COD removal in paddy soaked water was obtained by the method of aeration at $\mathrm{pH} 8$ using pond water, fish tank water and paddy field soil as microbial sources in 24 hours in the absence of light. This method was able to reduce COD below the Sri Lankan standards of discharging wastewater into irrigation lands. Combined methods of anaerobic digestion followed by coagulation with alum and anaerobic digestion followed by adsorption using commercial GAC also showed the COD removal below the discharge standards.

\section{Acknowledgement}

Financial support from the Senate Research Grant of the University of Moratuwa, Sri Lanka is gratefully acknowledged.

\section{References}

1. Ramalingam, N., Anthony Raj, S., "Studies on the Soak Water Characteristics in Various Paddy Parboiling Methods", Bioresource Technology, Vol. 55, pp 256-261, 1996.

2. Environment \& Management Lanka (Pvt.) Ltd. In association with Department of Chemical Engineering of the University of Moratuwa, Development of a low-cost technology for the treatment of rice mill effluents, Contract Research Project 12/412/307, December 1999, p.15.

3. Subramanian, V., Daksinamurthy, A., Nutrient loss during parboiling, II Riso, Vol. 26 No. 4, pp 337-340, 1977

4. Queiroz, M.I., Lopes, E. J., Zepka, L. Q., Bastos, R. G., Goldbeck, R., "The kinetics of the Removal of Nitrogen and organic matter from parboiled rice effluent by cyanobacteria in a stirred batch reactor", Bioresource Technology, Vol. 98, pp 21632169, 2007.

5. Bajpaia, R., Sharmab, N. K., Lawtonc, L. A., Edwardsc. C., \& Raia, A. K., "Microcystin producing cyanobacterium Nostoc sp. BHU001 from a pond in India", J. Toxicon, Vol. 53, No. 05, pp. $587-590,2009$

6. Håkanson, L., Bryhn, A. C., Hytteborn, J. K., "On the issue of limiting nutrient and predictions of cyanobacteria in aquatic systems", $J$. Science of the Total Environment, Vol. 379, No. 01, pp. 89-108, 2007.

7. APHA, AWWA, WPCF, Standard Methods for the Examination of Water and Wastewater, 18 ${ }^{\text {th }}$ Ed., American Public Health Association, Washington, 1992.

8. http://www.cee.vt.edu/ewr/environmental/te ach/wtprimer/jartest/jartest.html Visited $21^{\text {st }}$ May 2009.

9. http://www.geocities.com/CapeCanaveral/300 0/coag.html, Visited, 10 ${ }^{\text {th }}$ July 2008. 